\title{
Cultura organizacional y educativa: Un sincretismo para el éxito empresarial
}

\author{
Marcos Ruiz Ruiz \\ Universidad de Lima. Lima, Perú \\ Correo electrónico: mruiz@ulima.edu.pe \\ Ulrike Sallandt \\ Universidad de Bochum. Bochum, Alemania \\ Correo electrónico: ulrikesallandt@hotmail.com \\ Recibido: 23/3/2012 / Aprobado: 16/5/2012
}

Resumen: El propósito del presente artículo es reflexionar sobre la importancia de la cultura organizacional y explorar aquellos elementos que la determinan y convierten en un tema clave para el éxito de la empresa moderna. En este esfuerzo, procuraremos entender la estrecha relación que guarda con la función comunicadora, así como el papel que juega la acción educativa y formativa dentro de la institución. Analizaremos cómo la cultura empresarial, la educación y la comunicación guardan una relación compleja y de recíproca correspondencia. Bajo este enfoque, proponemos lo que hemos llamado un sincretismo estratégico entre los agentes que hacen posible la función comunicativa en la empresa, y la función educativa y formativa en el marco de la cultura organizacional.

Palabras clave: Cultura organizacional / empresa / comunicación / educación

\section{Organizational and educational culture: A syncretism for business success}

Abstract: The aim of this article is to explore the importance of organizational culture, specially those elements that determine it and become a key construct for the success of a modern business. In this effort, we will seek to understand the close relationship between communicational function and educational and training role within the institution. In the other hand, we will discover how the business culture, education and communication bear a complex relationship and mutual correspondence. Under this approach, we propose what we call a strategic syncretism between the agents that enable the communicational function in business, and the educational and training role within the organizational culture.

Keywords: Organizational culture / business / communication / education 


\section{INTRODUCCIÓN}

El término cultura ${ }^{1}$ es amplio y complejo, pero al restringirlo al ámbito empresarial debemos entenderlo como los valores, conocimientos, saberes y formas de interrelación que comparten los miembros de una organización en su esfuerzo por la consecución de los fines institucionales y colectivos. Para Edgar Schein (1988) la cultura de la corporación puede definirse como el

[...] conjunto de creencias -inventadas, descubiertas o desarrolladas por un grupo determinado al ir aprendiendo a enfrentarse con sus problemas de adaptación externa y de integración interna- que hayan ejercido la suficiente influencia como para ser consideradas válidas y, en consecuencia, ser enseñadas a los nuevos miembros como el modo correcto de percibir, pensar y sentir esos problemas.

Esta cultura empresarial, debidamente canalizada y con un claro derrotero, resulta fundamental para la consecución de mayor competitividad en el aprovechamiento de los recursos humanos y en la organización en general.

Los valores de la organización constituyen la base de toda cultura empresarial. Si no están claramente definidos e interiorizados, se corre el riesgo de no tener un horizonte. Según Miquel Porret "la filosofía de una empresa se expresa mediante valores y estos son la guía de la conducta cada día. Los valores significan todo aquello que es apreciado y estimado o digno de ser tenido como algo bueno" (Porret, 2010, p. 451). Por ejemplo, valores como la calidad del producto o servicio, la rapidez con que se brinda, la atención al cliente, el servicio posventa, el trabajo en equipo, el valor de la marca, etcétera, configuran la personalidad de la organización.

En esta línea, la dirección de la empresa y su forma de gestión empresarial son las principales responsables de tal definición axiológica y de la generación de una adecuada y pertinente cultura organizativa entre los miembros de la empresa. Tal modelo de gestión empresarial encierra un fuerte elemento educativo y formativo para con los trabajadores que se debe traducir, por un lado, en una adecuada comunicación de los valores y fines institucionales; y por otro, en un acompañamien-

1 Del latín 'cultura', que viene de cultus que significa cultivo o cultivado. 
to permanente y responsable de los individuos. El elemento formativo profesional al interior de la organización, redunda en el incremento sustancial del potencial de la empresa a través del perfeccionamiento profesional y humano de quienes la forman. Este proceso implica también el desarrollo y mejoramiento de capacidades, conocimientos y aptitudes del personal (Peña, 1999). De acuerdo con Miquel Porret (2010, p. 208) en este esfuerzo de la organización se busca dotar de conocimientos técnicos — pero también de acompañamiento psicológico- a los empleados para que desarrollen sus actividades con mayor profesionalidad. En cuanto a la empresa en su conjunto, se pretende optimizar sus recursos humanos a fin de conseguir mejores niveles de producción y mayor valor agregado.

En las próximas líneas ensayaremos una breve reflexión dentro de este enfoque de cultura organizacional y de cómo guarda estrecha relación con la responsabilidad de la dirección de la empresa, la comunicación y la función educativa y formativa que le compete.

\section{ALCANCES GENERALES SOBRE LA GESTIÓN EMPRESARIAL Y SU FUNCIÓN EDUCATIVA}

Una organización, desde un enfoque filosófico antes que práctico y productivo, implica el establecimiento de la coordinación entre un grupo de personas asociadas para alcanzar eficientemente unos fines que se entienden comunes. Tal coordinación trasciende el ámbito meramente productivo si quiere ser efectiva, para entrar en un terreno más complejo y sensible, que incluye el comportamiento y el desarrollo de las personas involucradas. Cabe puntualizar que el término 'organización' puede encerrar una gran cantidad de estructuras con los más variados y complejos objetivos, constituyéndose en un término mucho más amplio que el de 'empresa', aunque se empleen cotidianamente como sinónimos desde la perspectiva mercantilista tan arraigada en nuestras sociedades contemporáneas (Porret, 2010, p. 25).

Focalizándonos en el tema de la eficiencia organizacional y en la necesidad de trascender a las actividades estrictamente orientadas a la generación de valor, conviene hacer hincapié en la función vinculada al manejo de las relaciones entre las personas. En este sentido, la Dirección General y el Departamento de Recursos Humanos (RR. HH.) tienen acaso la tarea más compleja y delicada al tratar de que los individuos crezcan —en el sentido más ontológico del término- dentro de la 
organización, estimulando sus competencias al máximo y permitiendo que, progresivamente, desempeñen puestos de mayor responsabilidad. Detrás de esta importante función, se encuentra el sentido formativo y educativo de los responsables de la empresa. Una función educativa en esencia orientadora de personas y pedagógica —en el sentido más holístico del término - es esencial para conseguir una fuerza laboral estimulada, motivada y acompañada permanentemente para la consecución de la calidad de un servicio y la adaptación a las necesidades tecnológicas y estratégicas de la organización.

\subsection{La gestión empresarial moderna}

La filosofía en torno a la empresa y la gestión empresarial ha ido evolucionando a través del tiempo. Sin embargo la concepción sistémica de la empresa - entendida como un conjunto de factores de producción, económicos y sociales - sigue vigente en la medida en que permite su análisis como sistema abierto al exterior. En tal sentido, la empresa recibe inputs del entorno como los materiales, la energía, la información y la mano de obra; a fin de devolver outputs como el producto o servicio brindado, los sueldos de los empleados, los dividendos, entre otros (Gómez, 2009).

En cuanto a la gestión empresarial en concreto, la evolución de su concepción filosófica ha trascendido desde la perspectiva del manejo de una estructura organizacional reduccionista, que considera al hombre como extensión de la máquina y que obedece solo al impulso tecnológico, hasta entender el valor de la organización en cuanto a la gestión del capital humano y el desarrollo del conocimiento. De esta forma, "la tendencia actual conduce al operario a un gran control interno debido al compromiso (adhesión) con la organización, su preparación y capacidad para moverse en la autonomía, permitiendo una organización más achatada o plana en la que también jugará un papel preponderante el trabajo en equipo" (Porret, 2010, p. 46).

La cultura de la empresa varía según las características personales del factor directivo y de la misión, visión y políticas internas que recogen sus fines. Una cultura organizacional coherente con la perspectiva moderna y la filosofía anteriormente aludida debe tener una marcada 
orientación hacia el recurso humano. ${ }^{2}$ Tal orientación hacia las personas, se traduce en una función educativa a través de la comunicación de valores, del ejemplo como medio formativo y del espíritu de servicio hacia la comunidad empresarial. La confianza entre sus miembros se torna decisiva y el estilo participativo en las decisiones y el ejercicio del liderazgo se hacen evidentes, generándose una sensación familiar y un sentido de pertenencia que se ve fortalecido en la cotidianidad de la vida laboral.

\subsection{La dinámica empresarial y sus elementos educativos}

La organización como tal — a pesar de su compleja estructura y constitución en factores financieros, económicos y productivos- debe comportarse como una sola unidad. Bajo esta perspectiva, existen ciertos actores o elementos conformantes de tal unidad y de los factores anteriormente mencionados. Así, podemos encontrar elementos de tipo humano, elementos materiales y elementos inmateriales. Estos últimos también llamados activos intangibles o de capital intelectual (Gómez, 2009):

a) Elementos de tipo humano.- Son los propietarios del capital, los trabajadores administrativos, los directivos, los jefes de departamento, los operarios y los trabajadores en general.

b) Elementos materiales.- Son los correspondientes a la infraestructura, los edificios y locales, la maquinaria, la inversión técnica o bienes materiales, las mercancías, los recursos financieros, etcétera.

c) Elementos inmateriales o capital intelectual.- Son los constituidos por los activos intangibles de la empresa: el capital humano (y sus competencias y capacidades), el capital estructural (la organización y las tecnologías) y el capital relacional (en cuanto a las relaciones con clientes y proveedores).

De todos los elementos constitutivos de la unidad organizativa, aquellos correspondientes a los inmateriales, es decir el capital intelectual o activos intangibles, son los que merecen particular atención. Si bien la función educativa está asociada - en términos de orientación-a los elementos de tipo humano, su foco de acción directa es más

2 Existen también culturas empresariales orientadas preponderantemente al trabajo y al logro de objetivos, hacia las normas, hacia el poder y control, hacia los clientes, etcétera. 
específico en la medida en que se entienda como función de desarrollo de todo el espectro correspondiente al capital humano, dentro de los activos intangibles. Dicho capital humano

[...] se refiere al conocimiento —explícito o tácito- útil para las empresas que poseen las personas y equipos, así como a su capacidad para regenerarlo; es decir, su capacidad de aprender. El capital humano [...] es la base de la generación de los otros dos tipos de capital intelectual [es decir, el estructural y relacional]. ${ }^{3}$ Una forma de distinguir el capital humano es que la empresa no lo posee, no lo puede adquirir en propiedad, solo alquilarlo durante un periodo de tiempo (el tiempo que tiene a su servicio los recursos humanos) (Porret, 2010, p. 442).

Por su parte, el capital estructural corresponde al conocimiento que la organización logra explicitar y sistematizar. ${ }^{4}$ Este tipo de capital involucra aquellos conocimientos estructurados de los que depende la eficiencia de la empresa: los procesos y procedimientos de trabajo, sistemas y modelos de gestión, sistemas de información, patentes, tecnologías disponibles, etcétera. Todos ellos son propiedad de la empresa y constituyen los depósitos no humanos de conocimiento que quedan en la organización cuando los trabajadores se marchan.

Finalmente, el capital relacional está referido al valor de las relaciones que la organización mantiene con su entorno: clientes, proveedores, intermediarios, accionistas, entre otros agentes sociales y económicos (Porret, 2010). El Modelo Intelect de Euroforum (1998) resume muy bien la constitución del capital intelectual dentro del valor de la empresa y se puede apreciar en la figura 1.

Volviendo al tema de los elementos inmateriales, y más concretamente al capital intelectual de la empresa, conviene hacer hincapié en que la función educativa empresarial tiene una acción decisiva frente al desarrollo del mencionado capital y específicamente en cuanto al capital humano se refiere. Es decir, el objeto y sujeto principales de la función orientadora y formativa de la Dirección de Recursos Humanos (RR. HH.) deben estar focalizados en el seguimiento de las competencias, capacidades y habilidades (sociales y psicológicas) de este tipo de capital de la organización. Tal seguimiento debe consistir no solo en la

3 Resaltado de los autores.

4 La gestión del conocimiento. 
Figura 1

Constitución del capital intelectual de una empresa

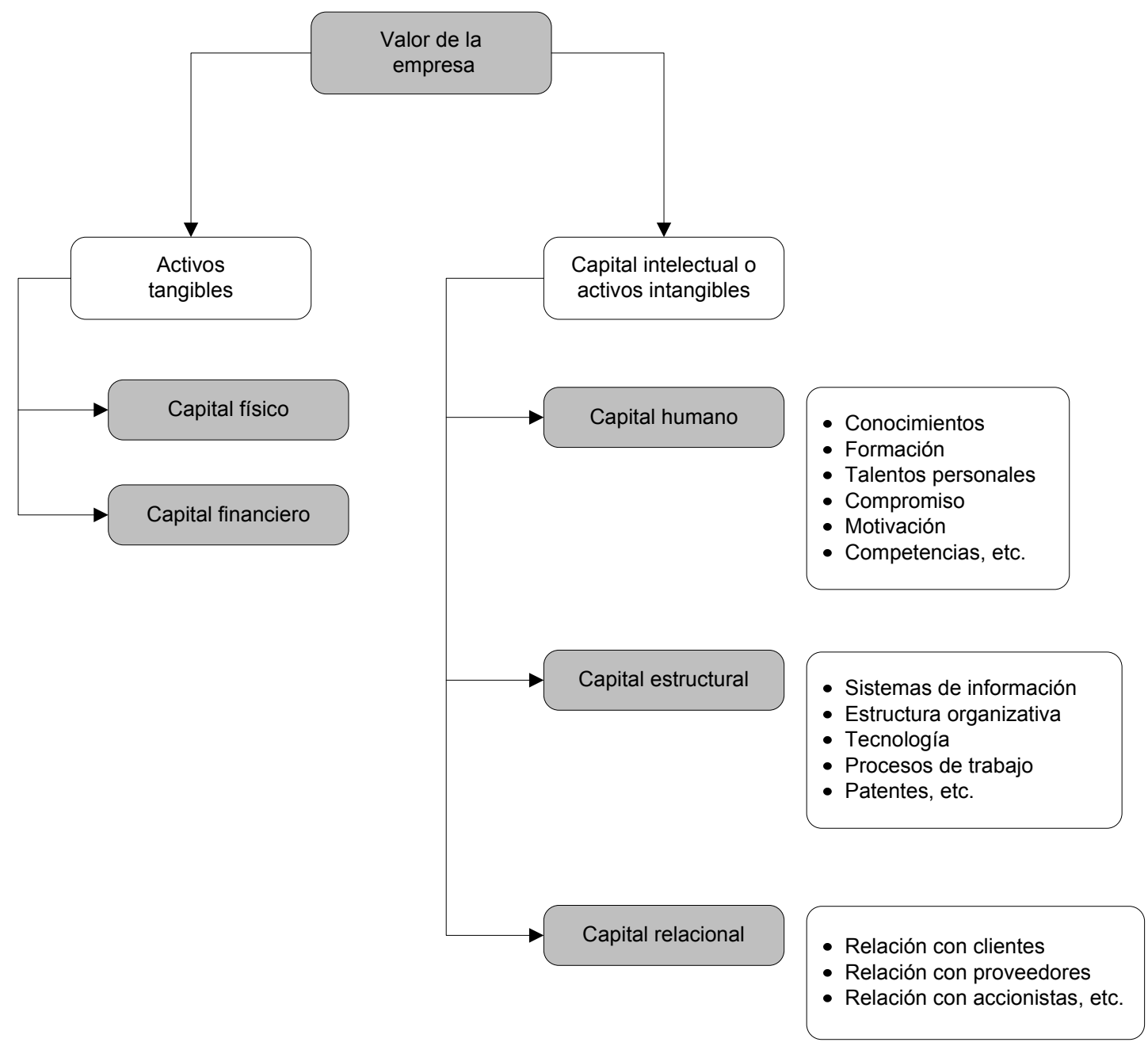

Fuente: Modelo Intelect 1998 de Euroforum (Fundación Iberoamericana del Conocimiento). Recuperado en marzo del 2012 de http://www.gestiondelconocimiento. com/modelos.htm.

Elaboración y diseño propios. 
programación de actividades instructivas o de capacitación profesional que busquen desarrollar talentos individuales del personal; sino antes, en prever acciones tan importantes como el adecuado acompañamiento psicológico y emocional, el manejo formativo de la evaluación y de la sanción como oportunidad de mejora (antes que de simple acción punitiva), etcétera. ${ }^{5}$ Un trabajador adecuadamente formado en una empresa siente pertenencia hacia su institución. Tal sentido de pertenencia se traduce en mejores equipos de trabajo y en mayor capacidad de liderazgo. El buen gerente sabe qué decir y cuándo hacerlo. Sabe también si conviene hacerlo públicamente o a puertas cerradas. Así como educa a través del ejemplo y permite formar en valores creando fidelidad y lealtad para con la empresa y sus directivos.

Finalmente, cabe acotar que la herramienta estratégica para llevar a cabo esa función educadora y formativa del capital humano de la organización, es — como estudiaremos a continuación — una pertinente acción comunicativa que debe traducirse en un adecuado diálogo productivo y a todo nivel, por el bien de toda la cultura organizacional.

\section{LA COMUNICACIÓN ORGANIZACIONAL COMO MARCO DE REFLEXIÓN}

\subsection{Principios y fundamentos de la comunicación}

La comunicación abarca todo el espectro de la vida humana; es decir, la vida se manifiesta con carácter comunicativo porque solo existe de forma relacional. Ningún ser viviente es capaz de mantenerse en este estado vital sin ponerse en contacto con algo o con alguien; por ello, cada relación entre seres humanos, desde la misma génesis de la humanidad, se estableció haciendo uso del carácter comunicativo. Las conexiones interpersonales entienden la comunicación como el medio de contacto y conexión entre los seres vivientes, y particularmente la comunicación oral y escrita, en el caso de los hombres, como bases para su interacción. Obviamente debemos acotar que existe una amplia gama de diferentes enfoques y formas comunicativas si partimos

5 Otra forma de educar en la empresa moderna - aún incipiente en nuestro entorno- es la formación a través de la gestión de la diversidad social: una forma de integración de todas las sensibilidades, tendencias y características humanas de la organización que busca armonizar las relaciones entre grupos diferentes recusando cualquier tipo de discriminación (Porret, 2010, pp. 422-423). 
del axioma de que la conducta humana es en sí misma comunicación y "se deduce que por mucho que uno lo intente, no puede dejar de comunicarse" (Watzlawick et al., 1995, p. 50).

La humanidad se establece en el tiempo como toda una cultura de comunicación. Donde hay vida humana, hay relación comunicativa. La vida cotidiana implica siempre intercambio de mensajes que puede darse de forma oral, visual o corporal (Fiske, 1984, pp. 57-59). En consecuencia, la comunicación se puede definir como "la transferencia de un mensaje de $A$ a $B$, y sus principales intereses están en medio del canal, el trasmisor, el receptor, la interferencia y la retroalimentación, porque todos estos procesos se relacionan al momento de enviar un mensaje" (Fiske, 1984, p. 33). Este contacto o interacción comunicativa (West y Turner, 2005), sea intencional o no, está bajo la influencia de fuertes factores externos a la situación personal en la que los interlocutores se insertan; y no solo de su propio contexto interno y presente. Nos referimos a todo aquello del pasado que ya escribió la historia del emisor y el receptor. Esta particular relación caracteriza la vida y es fundamental para comprender la estructura organizacional y cultural del hombre (Marchori, 2010, p. 3).

En los procesos de relación interpersonal y en medio de la coexistencia humana,${ }^{6}$ el envío de un mensaje con determinada significación a través de un código o conjunto de signos (Fiske, 1984, pp. 33-52), puede sufrir modificaciones o distorsiones interpretativas y subjetivas por una diversidad de interferencias. Como consecuencia de ello, el receptor no decodifica correctamente el mensaje emitido, corriendo el riesgo de interpretarlo sesgadamente y creando una versión distorsionada de este. Desde luego, y a causa de la subjetividad del receptor, ningún mensaje recibido es ciento por ciento idéntico al originalmente enviado. El nivel de distorsión también se verá afectado según la cantidad de influencias y obstáculos externos al proceso comunicativo.

Por otro lado, los requisitos fundamentales de un sistema comunicativo - es decir, el emisor, el receptor, el mensaje o sistema de signos y códigos, y el medio de comunicación (sea del lenguaje oral o escrito, del cuerpo, de los gestos, etcétera) - se constituyen en forma muy particular por su estrecha relación con la cultura. Por ello, la comunicación intercultural $-\mathrm{o}$ entre diferentes contextos culturales- se torna com-

6 Que gracias a la acción comunicativa pasa a tener carácter de convivencia antes que de simple coexistencia. 
pleja y complicada. Así, considerando la premisa de la existencia de una dependencia mutua entre significación y cultura (Fiske, 1984, p. 120), tales circunstancias obstaculizan el proceso comunicativo y exigen uniformizar ciertos requisitos elementales - para poder convertir el coexistir en un convivir consciente- a través de una comunicación funcional y efectiva. En este esfuerzo, y para poder limitar una posible interferencia entendida, "[...] como cualquier cosa añadida a la señal entre su transmisión y su recepción sin intención de su fuente [...]" (Fiske, 1984, p. 3), la redundancia posee un valor decisivo que puede favorecer la comunicación en aras de hacerla comprensiva. Podríamos acotar que el emisor que "[...] incorpora la redundancia en su mensaje, se centra en su audiencia: quiere lograr la comunicación. Quien no lo hace está más preocupado por sus propios contenidos [...]. Así vemos que la redundancia se relaciona más con la eficiencia de la comunicación y con la solución de problemas de comunicación" (Fiske, 1984, p. 8).

Sobre la base de lo anteriormente expresado y enfocados siempre en el carácter relacional del individuo y su necesidad de sociabilidad a través de la comunicación, se puede definir con más precisión este fenómeno comunicativo como "[...] un proceso social [...] que implica a personas [...] que interactúan con diferentes intenciones, motivaciones y habilidades. [En tal sentido] la comunicación es dinámica, compleja y continuamente cambiante" (West \& Turner, 2005, p. 5). Complementariamente, los diferentes modelos teóricos muestran que una comunicación puede ser un proceso lineal (Shannon \& Weaver, 1949), de interacción (Schramm, 1954) o transaccional (Barnlund, 1970) (West $\&$ Turner, 2005, pp. 9-10). Mientras el primero considera a los interlocutores únicamente en su ser emisor o receptor, el segundo los analiza en su relación y el tercero - yendo más allá- resalta el carácter productivo de este tipo de vínculo cooperativo.

Esta complejidad de principios y fundamentos del proceso comunicativo, más aún en medio de nuestra sociedad contemporánea y de la globalización de la información y la comunicación, implica reconocer grandes desafíos, sobre todo en el campo ético. Por ejemplo, en relación con la existencia o no de límites y particularidades que debemos considerar durante el proceso de comunicación dentro de una cultura organizacional. A continuación seguiremos desarrollando y reflexionando en torno a este desafío conceptual, considerando ahora la realidad empresarial contemporánea y su concreta dimensión formativa y educativa. 


\subsection{Comunicación en la empresa: Oportunidades y riesgos}

Partiendo de la premisa de que la organización es producto de una interacción humana y siendo la empresa una organización, ella también termina caracterizándose por la acción y la comunicación (Marchiori, 2010, pp. 3-4). Los avances en el estudio de las organizaciones la entienden como imagen de un fenómeno social y de una forma particular de expresión humana. Es por ello que se "[...] entiende que la comunicación sea uno de los elementos concurrentes, igualmente constitutivos y contingentes de las posibilidades de una organización" (Marchiori, 2010 , p. 5). Este papel funcional de la comunicación tiene implicancias en la generación de muchas oportunidades que contribuyen al proceso de mejora continua en una empresa, por ejemplo, en cuanto a la posible apertura de la organización empresarial hacia su contexto externo o a su interacción permanente con el entorno sociocultural. Así, se genera una gran habilidad para la adaptación al cambio de manera creativa e innovadora. Esta comunicación abierta evita que el sistema empresarial se convierta en un cuadro estático, se aleje de la realidad, y por tanto del desarrollo que mantiene su competitividad. Por el contrario, la organización se convierte en su propia constructora y creadora, en agente activo y pasivo; es decir, en emisora y receptora de diversos mensajes producto de la interacción externa e interna (Luhmann, 1992). Se genera entonces un verdadero tejido de relaciones sumamente complejas, en donde el gran éxito radica en la comprensión de tal complejidad como única realidad de nuestros tiempos (Morin, 2001). En este sentido, la comunicación empresarial se hace efectiva únicamente en la medida de una real apertura y postura crítica — de carácter relacional- orientada por un espíritu participativo con todo el personal, con un fundamento sólido y con objetivos claramente (re)definidos.

Estas grandes oportunidades de la comunicación pueden acarrear al mismo tiempo un riesgo: el cambio en la comprensión de la cultura organizacional como fenómeno social y humano, genera al mismo tiempo una serie de debilidades. Las exigencias y desafíos para los recursos humanos de la empresa se incrementan significativamente debido a que las propias conductas sociales deciden sobre el adecuado funcionamiento de su sistema comunicativo y, en consecuencia, sobre la buena marcha de la empresa. 
Como mencionamos anteriormente, la empresa moderna debe poner especial énfasis en el Departamento de Recursos Humanos (RR. HH.), clave interna para involucrarse con los miembros de la organización y para la inducción del personal. Esta última corresponde al "[...] proceso mediante el cual los recién llegados aprenden los valores y las normas de la organización y asimilan las conductas que son necesarias para realizar bien su trabajo" (Jones \& George, 2010, p. 101). Sin embargo, al ser los mismos individuos los ejecutores de la función comunicativa podrían convertirla en una acción de búsqueda de influencias y medio de manipulación externa. Los problemas entre el personal de una organización - más aún si se trata de una organización vertical y jerárquica entre directores o jefes y empleados - se origina a causa de una deficiente comunicación y por falta de buenas relaciones. Es decir, por la convivencia dentro de un clima laboral particularmente conflictivo y dominado por la incertidumbre, la desconfianza y el aislamiento. La teoría señala que "a medida que la incertidumbre se va reduciendo, la cantidad de comunicación verbal aumenta" (West \& Turner, 2005, p. 146). En consecuencia, surge una realidad compleja de la sociedad contemporánea, que muchas veces se presenta también como complicada, confusa y caótica, y se establecen reacciones muy humanas de carácter manipulador, agresivo y evasivo. Este es un mensaje propio de una deficiente identidad e inestabilidad de las personalidades dentro de un medio social. En este contexto, la realidad empresarial no brinda las condiciones necesarias para el adecuado desarrollo de un sistema comunicativo. Las barreras comunicativas que se generan y producen pueden ser muy concretas y de carácter material, fisiológico, semántico o psicológico (Gonzales \& Olivares, 1999).

En medio de todos estos obstáculos de clima laboral desfavorable y que solo transmite desconfianza, hay una gran necesidad formativa y educativa para permitir la construcción de bases sólidas e indispensables para el buen desarrollo de la organización empresarial. La clave radica en convertir tales problemas en desafíos y solucionar los conflictos a través de la confianza, el diálogo y la colaboración:

[...] un diálogo [...] con apertura, honestidad y colaboración, alimentará la confianza entre los miembros de la organización. Los conflictos siempre van a existir, pero debemos recordar que deben ser funcionales y no disfuncionales; es decir, deben terminar favoreciendo a las partes involucradas (Martínez, 2011). 


\section{GESTIÓN DIRECTIVA Y DIÁLOGO: EL SINCRETISMO ESTRATÉGICO}

Partiendo de la premisa de que una empresa moderna se caracteriza por la comunicación organizacional, surge por parte de ella la necesidad de asumir un papel formativo y educativo que contribuya a la generación de competencias comunicativas. El éxito de la gestión depende - en primer lugar - de la capacidad de crear un ambiente con un sistema de comunicación eficiente. Tal sistema abarca toda la realidad empresarial: desde el planteamiento de los objetivos - atravesando por los procedimientos y procesos productivos - hasta la etapa final de evaluación y retroalimentación. La comunicación se convierte entonces en la amalgama entre todas estas etapas y se constituye como herramienta de transmisión e interacción entre todos; empezando por el principal emisor: el gerente. Este debe promover desde el inicio y de manera permanente la integración o penetración social de los trabajadores. ${ }^{7}$ Así, sobre la base de un liderazgo horizontal y coherente con la empresa moderna, el gerente ha de trabajar la dimensión social de su personal. Ha de crear un espacio de libre comunicación que facilite la socialización y plantee las bases que desarrollen un sentido de pertenencia hacia la institución.

La empresa, como colectivo social, trabaja a través de procesos grupales. En consecuencia, la organización empresarial es de carácter relacional y comunicacional a la vez; "[...] y sus objetivos [...] se logra[n] mediante los esfuerzos integrados y coordinados de más de una persona, es decir, de un grupo de personas que se dan a la tarea juntos [...] o separados, pero siempre cooperativamente [...]" (Gonzales \& Olivares, 1999, p. 157). Esta postura subraya claramente la necesidad y el significado de las competencias comunicativas requeridas en el gerente para con todo su personal, a fin de generar el clima de trabajo favorable y focalizado en resultados que superen las actitudes disfuncionales para reemplazarlas por aquellas de carácter funcional: como el animar, estimular y buscar consensos (Gonzales \& Olivares, 1999, p. 168).

Si bien decimos que la empresa tiene un carácter grupal, su gestión está principalmente bajo responsabilidad del gerente (el líder) antes que de otro miembro de la organización. En tal sentido, sus competencias comunicativas constituyen un aspecto decisivo para el desarro-

7 Según la Teoría de penetración social las relaciones entre las personas varían de acuerdo con el nivel de dicha penetración (West \& Turner, 2005, p. 158). 
llo y el éxito empresarial. Tales competencias comunicativas, ${ }^{8}$ a pesar de estar preferentemente vinculadas al contexto de la lingüística, se aplican también a la realidad empresarial y al propio gerente, que al emplearlas como herramienta genera lo que llamamos un 'sincretismo estratégico'. Conviene puntualizar que:

[...] la competencia comunicativa tiene un carácter eminentemente estratégico, tanto en lo individual como en lo colectivo y representa un requisito para entablar relaciones no solo saludables sino también productivas que, en el ámbito de las organizaciones, contribuyen a sostener el clima organizacional, el sentido de pertenencia y todos aquellos componentes que optimizan los procesos productivos (Bermúdez \& Gonzales, 2011, p. 97).

En conclusión, el éxito de la empresa moderna depende fundamentalmente de la capacidad comunicativa del gerente y de cómo este asume un rol educativo y formativo con su personal. Los tiempos de estrategias mecanizadas, focalizadas exclusivamente en índices de resultados fríos y a espaldas del trabajador, pertenecen al pasado. En la actualidad se debe comprender la realidad empresarial como fenómeno social y desde una visión holística.

Esta perspectiva implica la aceptación de una diversidad de posturas que se logra armonizar solamente a través de un autocontrol emocional (Bermúdez \& Gonzales, 2011, p. 104). En medio de este contexto, tanto el gerente empleador como los empleados entran en una dinámica de enseñanzas y aprendizajes mutuos y continuos, donde todos asumen en su momento los roles de emisor y receptor. Se construye así un nuevo saber y hacer que favorece la vida organizacional. Mantener este clima laboral exige optimizar constantemente la competencia comunicacional como elemento formativo y como estrategia motivacional y de desempeño laboral. Este aspecto es decisivo para el crecimiento de la empresa y el aseguramiento de su éxito productivo.

8 "[...] la competencia comunicativa es vista como un compendio de saberes capacidades, habilidades o aptitudes que participan en la producción de la convivencia y las relaciones interpersonales e intergrupales [sic], ya que la coexistencia humana requiere la mediación de una eficaz comunicación [...]" (Bermúdez \& Gonzales, 2011, p. 96). 


\section{CONCLUSIONES A MODO DE REFLEXIÓN}

La cultura organizacional termina siendo una realidad compleja e intangible, pero vital y clave para el desarrollo y el éxito empresarial. Una adecuada cultura de empresa redunda en beneficio no solo de la organización, sino principalmente de las personas involucradas en todo el sistema productivo. Por ello, la otrora concepción de empresa centrada en un mal entendido liderazgo, que se desarrollaba a espaldas del personal y con una verticalidad que no permite una comunicación fluida entre sus miembros, debe dar paso a la nueva concepción empresarial. Esta empresa moderna y exitosa, no solo se enfoca en la producción y el mercado, sino también en el bienestar de su capital humano. Una empresa de vanguardia es consciente de su imperativo de responsabilidad social y se entiende a sí misma como horizontal: no por la ausencia de jerarquías, sino por una constante apertura al diálogo y al ejercicio responsable de la comunicación. El buen clima laboral se retroalimenta con un adecuado factor comunicativo y viceversa.

La comunicación, entendida de esta manera, constituye una poderosa arma para formar y educar al propio capital humano tanto en valores y principios institucionales, como en aspectos de interrelación personal y social. La cultura organizacional se torna entonces una convivencia armónica, antes que una coexistencia forzada entre los factores y agentes productivos. Porque la experiencia lleva al entendimiento de que educar es convivir en un espacio de aceptación recíproca, donde las emociones y las acciones de las personas se van transformando y complementando (Maturana, 1996, p. 73). En buena cuenta, es un ambiente de respeto, de diálogo, de formación y comunicación abierta. Agregaríamos finalmente - y para el ámbito de la vida empresarial y laboral-que solo entonces se logra un espacio organizacional verdaderamente productivo, en el sentido más amplio de su acepción: una cultura empresarial educativa, exitosa y feliz.

\section{REFERENCIAS}

1. Beck, K. (2007). Kommunikationswissenschaft. Stuttgart: UTB.

2. Bermúdez, Lily \& González, L. (2011). La competencia comunicativa: Elemento clave en las organizaciones. Quórum Académico, 8(15). Maracaibo: Universidad de Zulia. 
3. Davis, Flora (1976). La comunicación no verbal. Madrid: Alianza Editorial.

4. Euroforum (1998). Modelos de medición del capital intelectual: Modelo Intelect 1998. Fundación Iberoamericana del Conocimiento. Recuperado el 13 de marzo de 2012, de http:// www.gestiondelconocimiento.com/modelos.htm

5. Fiske, John (1984). Introducción al estudio de la comunicación. Bogotá: Norma.

6. Gómez, María del Mar (2009). Retórica en la empresa. Las habilidades comunicativas del directivo empresarial. Covilhã: Libros LabCom. Recuperado el 14 de marzo de 2012, de http://www. livroslabcom.ubi.pt/pdfs/20110818-maria_del_mar_comunicacion_2009.pdf

7. González, Martín \& Olivares, Socorro (1999). Comportamiento organizacional: Un enfoque latinoamericano. México, D.F: CECSA.

8. Jones, Gareth R. \& George, Jennifer (2010). Administración contemporánea. (6 ${ }^{\text {a }}$. ed.). México, D. F.: McGraw-Hill.

9. Karmasin, Matthias; Rath, Matthias y Thomas, Barbara (2012). Kommunikationswissen als Integrationsdisziplin VS Verlag für Sozialwissenschaften. S/l, Alemania: s/e.

10. Luhmann, Niklas (1992). Die Wissenschaft der Gesellschaft. Aufl. 6. Frankfurt/M: Suhrkamp Verlag.

11. Marchiori, Marlene (2010). ¿Por qué hoy en día precisamos cultura organizacional? Una perspectiva de comunicación única en el área posmoderna. Diálogos de la Comunicación, 80, (abr.-jun.). Santiago de Cali: Felafacs.

12. Martínez Torres Lara, Arturo (2011). Solución de conflictos: confianza, diálogo y colaboración. Empresas \& Negocios, 498(10). Lima: Cámara de Comercio de Lima.

13. Maturana, Humberto (1996). El sentido de lo humano. Santiago de Chile: Dolmen.

14. Meyen, Michael \& Löblich, Maria (2006). Klassiker der Kommunikationswissenschatften. Fach-und Theoriegeschichte in Deutschland. Deutschland: Uvk 
15. Morin, Edgar (2001). Introducción al pensamiento complejo. Barcelona: Gedesa.

16. Peña Baztan, Manuel (1999). La psicología y la empresa. El factor humano. Barcelona: Hispano Europea.

17. Pinilla García, Helena (2006). La comunicación organizacional en el Perú: Modelos de diseño y gestión. (Tesis de licenciatura inédita). Lima: Universidad de Lima.

18. Porret, Miquel (2010). Gestión de personas: Manual para la gestión del capital humano en las organizaciones. Madrid: ESIC.

19. Schein, Edgar (1988). La cultura empresarial y el liderazgo. Barcelona: Plaza \& Janés.

20. Schmitt, Wolfgang J. (2011). Business-Kommunikation. German Edition-Kindle Ebook. Deutschland: Trainplan.

21. Watzlawick, Paul et al. (1995). Teoría de la comunicación humana. Buenos Aires: Tiempo Contemporáneo.

22. West, Richard \& Turner, Lynn (2005). Teoría de la comunicación. Análisis y aplicación. Madrid: McGraw-Hill.

23. Wolf, Mauro (1987). La investigación de la comunicación de masas. Barcelona: Paidós. 